\title{
Simple Catalytic Currents at DME for Trace Amounts of Cerium(IV) in Water Samples
}

\author{
C. GIRIDHAR, T. NIRANJAN and N.V.S. NAIDU*
}

Department of Chemistry, S.V.University, Tirupathi- 517502, A.P., India

nvsn69@gmail.com

Received 20 September 2012 / Accepted 20 October 2012

\begin{abstract}
A catalytic polarographic method for the determination of microgram quantities of $\mathrm{Ce}$ (IV) is developed based on the catalytic currents of cerium(IV) in the presence of $\mathrm{NH}_{4} \mathrm{Cl}-\mathrm{NH}_{4} \mathrm{OH}$ at $\mathrm{pH}$ 6.2 with piperazine. Piperazine produces catalytic current with $\mathrm{Ce}(\mathrm{IV})$ at peak potential -0.1 to $-0.6 \mathrm{~V}$ vs. SCE. The procedure was applied for the estimation of $\mathrm{Ce}(\mathrm{IV})$ in water samples. The method is simple, sensitive and free from interference of many metal ions.
\end{abstract}

Keywords: D.C.Polarography, Catalytic currents, Cerium(IV), Piperazine, Water samples, Differential pulse polarography

\section{Introduction}

Analytically, cerium in its tetravalent state differs significantly from all other lanthanides due to its immense oxidizing ability in acidic solutions. It is a popular oxidant in analytical $^{1}$ and organic ${ }^{2}$ application, because it is highly reactive, inexpensive and readily available in high purity. $\mathrm{Ce}(\mathrm{IV})$ has also been used as oxidant in studies of the homogeneously ${ }^{3}$ and heterogeneously ${ }^{4}$ catalyzed oxidations of $\mathrm{H}_{2} \mathrm{O}$ to $\mathrm{O}_{2}$ and $\mathrm{Cl}^{-}$to $\mathrm{Cl}_{2}$. Cerium is industrially important and is used in nuclear reactor; alloys with nickel and chromium; microwave devices, lasers and masers and television sets ${ }^{5,6}$. The oxalate salts of the metal have been used to remedy vomiting during pregnancy, while other salts of the metal have been used depressants of the central nervous system, astringents and antiseptics ${ }^{5}$. The increasing industrial use of cerium and reports on cerium toxicity makes it essential to have analytical procedures suitable for monitoring cerium in the environment and related fields. This necessitated the development of convenient and reliable analytical methods for the determination of cerium. Analytical techniques, such as ICP - $\mathrm{AES}^{7-9}$, or electrothermal vaporization ICP - AES after HPLC separations ${ }^{10,11}$, spectrofluorometry ${ }^{12,13}$, striping voltammetry ${ }^{14,15}$ reported for the determination of cerium are of high cost and may not be available at most laboratories. Spectrophotometric determination of cerium ${ }^{16}$ is based on the catalytic effect of cerium; many kinetic spectrophotometry methods for the determination of cerium have been established ${ }^{17-21}$. 
It is desirable to develop a more facile, sensitive, selective, rapid and economical method for the determination of cerium(IV) in various water samples by using piperazine that gives catalytic currents with the metal at dropping mercury electrode (DME). The results are compared with differential pulse polarography.

\section{Experimental}

The current - voltage curves were recorded using a D.C. polarographic analyzer, model CL - 357 coupled with model LR - 101 strip chart recorder manufactured by Elico Private Ltd (Hyderabad, India). Effects of mercury height on polarographic currents were studied using D.C. recording polarograph model CL - 25 of Elico Pvt Ltd, Hyderabad.

\section{Differential pulse polarograph}

The current - voltage curves were recorded using polarographic analyzer, model CL - 362 coupled with optional printer manufactured by Elico Private Limited (Hyderabad, India). All pH measurements are made using pH meter, model LI - 120(Elico Pvt. Limited, India) with combined electrode of $\mathrm{pH}$ range $0-13$.

\section{Reagents}

A 99\% pure piperazine obtained from Sigma - Aldrich Chemical Laboratory, USA was accurately weighed and dissolved in double distilled water and used as the stock solution. Stock solutions of the $\mathrm{Ce}(\mathrm{IV})\left\{\left(\mathrm{NH}_{4}\right)_{4}\left[\mathrm{Ce}\left(\mathrm{SO}_{4}\right)_{4}\right] .2 \mathrm{H}_{2} \mathrm{O}\right\}$ were prepared from accurately weighed ammonium ceric sulphate AnalaR samples by dissolving in distilled water and diluted to required strength with double distilled water. The supporting electrolyte, ammonium chloride used in the present study was of AnalaR grade. Triton X - 100 was weighed and made up to $100 \mathrm{~mL}$ in a standard flask and diluted as per requirement.

\section{Procedure}

A measured amount of the supporting electrolyte, ligand and maximum suppressor were added to the required aliquots of Ce(IV) solution under study and the solution was made up to $25 \mathrm{~mL}$ with triple distilled water. This was then transferred to the polarographic cell and deoxygenated by passing nitrogen and polarographed. A test run of the supporting electrolyte without the electroactive species was also taken in order to record residual current (Figure 1).

\section{Results and Discussion}

Various optimal conditions developed for the determination of cerium(IV) at DME are reported below.

\section{Effect of $p H$}

The effect of $\mathrm{pH}$ on solutions containing $3.0 \mathrm{ppm}$ of cerium(IV) ion in $0.2 \mathrm{M}$ ammonium chloride was studied, using $0.1 \times 10^{-6} \mathrm{M}$ of piperazine as complexing agents, varying the $\mathrm{pH}$ from 5.0 to 9.0 adjusting with ammonium hydroxide. With increasing $\mathrm{pH}$, the height of the catalytic wave increased and after attaining a maximum peak current at $\mathrm{pH} 6.2$ for piperazine. The wave height decreased with further increase in $\mathrm{pH}$. The maximum wave height of the polarograms was selected as optimum $\mathrm{pH}$ which was maintained in all other studies. The results are graphically presented in Figure 2.

\section{Effect of supporting electrolyte concentration}

Nature of the catalytic hydrogen peak was studied by changing the ammonium chloride concentration in the range of 0.05 to $0.5 \mathrm{M}$ at DME, keeping the cerium(IV) concentration at $3.0 \mathrm{ppm}$ and ligand concentration at $0.1 \times 10^{-6} \mathrm{M}$ of piperazine and adjusting the $\mathrm{pH}$ to 6.2 for piperazine. 


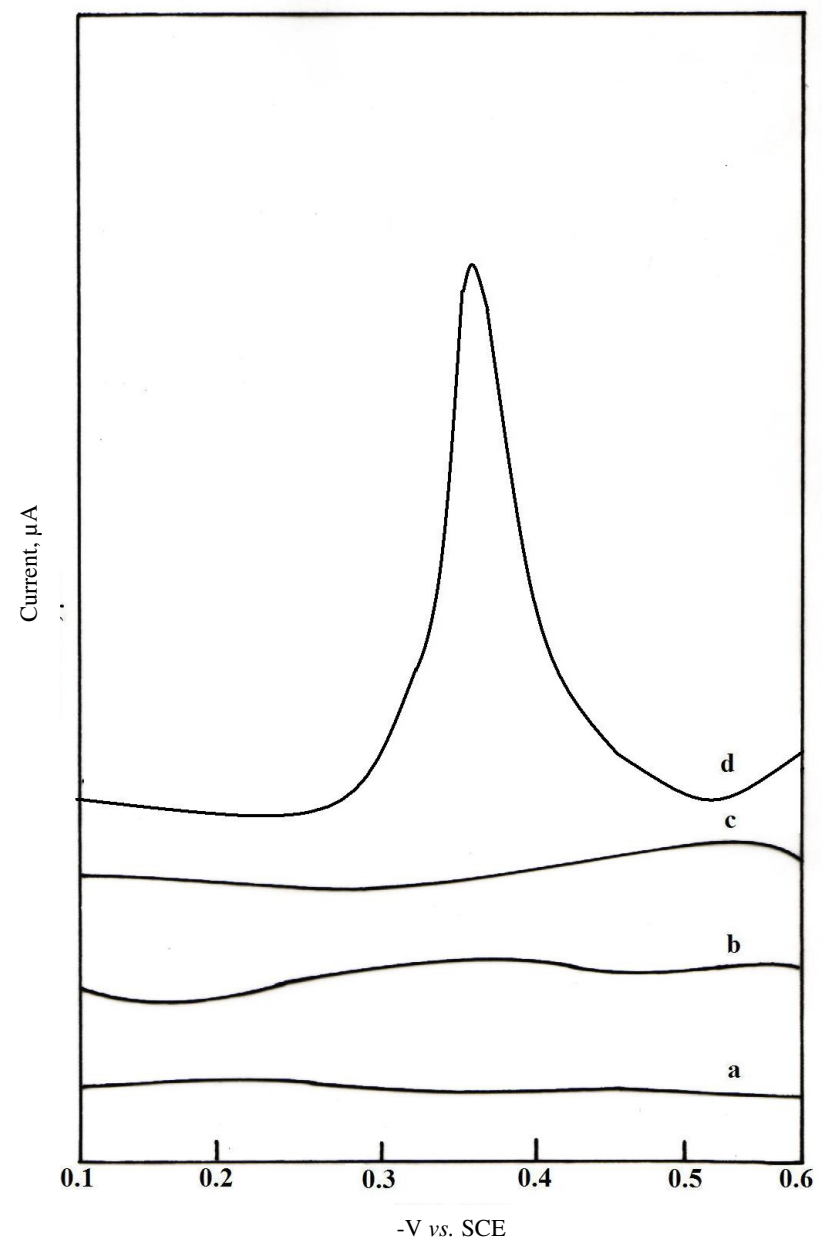

Figure 1. Polarographic curves of cerium(IV) in $\mathrm{NH}_{4} \mathrm{Cl}-\mathrm{NH}_{4} \mathrm{OH}$ medium in the presence of piperazine; (a) $0.15 \mathrm{M} \mathrm{NH}_{4} \mathrm{Cl}, \mathrm{pH} \sim 6.2$; (b) a $+0.5 \times 10^{-6} \mathrm{M}$ piperazine; (c) a $+3.0 \mathrm{ppm}$ $\mathrm{Ce}(\mathrm{IV}) ;(\mathrm{d}) \mathrm{b}+3.0 \mathrm{ppm} \mathrm{Ce}(\mathrm{IV})$

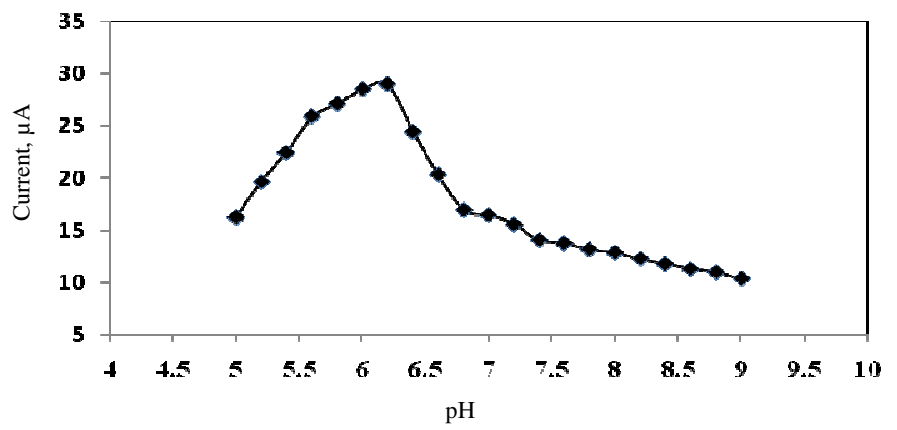

Figure 2. Effect of $\mathrm{pH}$ for the determination of cerium(IV) in various drinking water samples using piperazine with catalytic current technique at DME 
The polarograms are well defined in $0.15 \mathrm{M} \mathrm{NH}_{4} \mathrm{Cl}$ for ligand and the peak height increased up to $0.15 \mathrm{M}$. The peak height decreased beyond this concentration and therefore, $0.15 \mathrm{M}$ concentration was maintained for further studies and the results obtained are given in Figure 3.

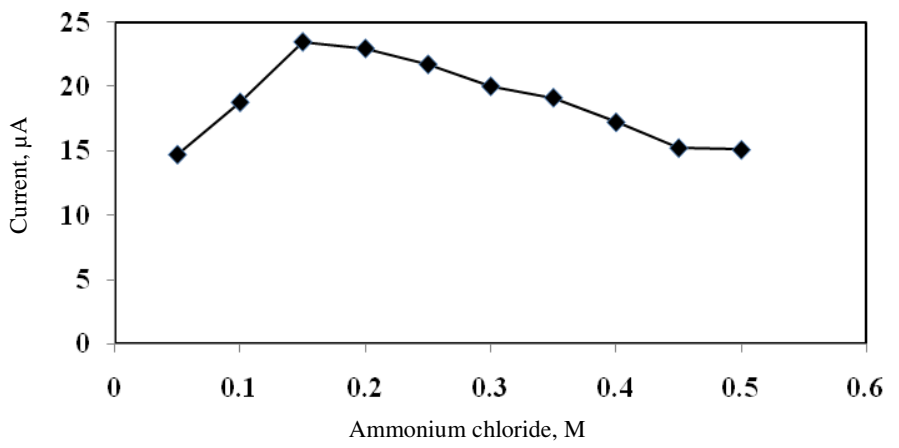

Figure 3. Effect of supporting electrolyte for the determination of cerium(IV) in various drinking water samples using piperazine with catalytic current technique at DME

\section{Effect of reagent concentration}

Series of solutions containing $3.0 \mathrm{ppm}$ of cerium(IV), $0.15 \mathrm{M}$ ammonium chloride with $0.1 \times 10^{-6}$ to $1.0 \times 10^{-6} \mathrm{M}$ ligand were polarographed, maintaining the $\mathrm{pH}$ of the solution at 6.2 for piperazine. The peak current does not vary linearly with all concentrations of ligand which is a typical characteristic nature of catalytic waves and the results obtained are represented graphically in Figure 4. From the results it is seen that the peak height increased linearly with ligand concentration only up to $0.5 \times 10^{-6} \mathrm{M}$ for piperazine. With further increase in ligand concentration the wave height is independent of concentration and shows that the complex was stable. Therefore, the concentration of the ligands where the maximum wave height obtained is fixed for quantitative studies. The peak potential of the catalytic wave shifted towards more negative potentials on increasing the ligand concentration, up to the maximum concentration reported above and remained constant beyond these concentrations. Plot of $\left\{[\right.$ Ligand $\left.] / i_{p}\right\}$ vs. [ligand] was a straight line (Figure 5) and confirms that adsorption phenomenon was involved in the electrode reaction process.

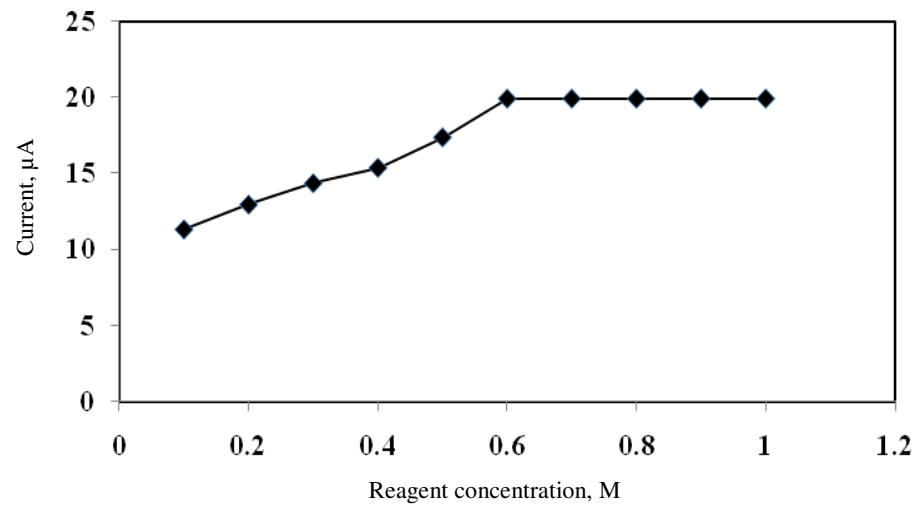

Figure 4. Effect of reagent concentration for the determination of cerium(IV) in various drinking water samples using piperazine with catalytic current technique at DME 


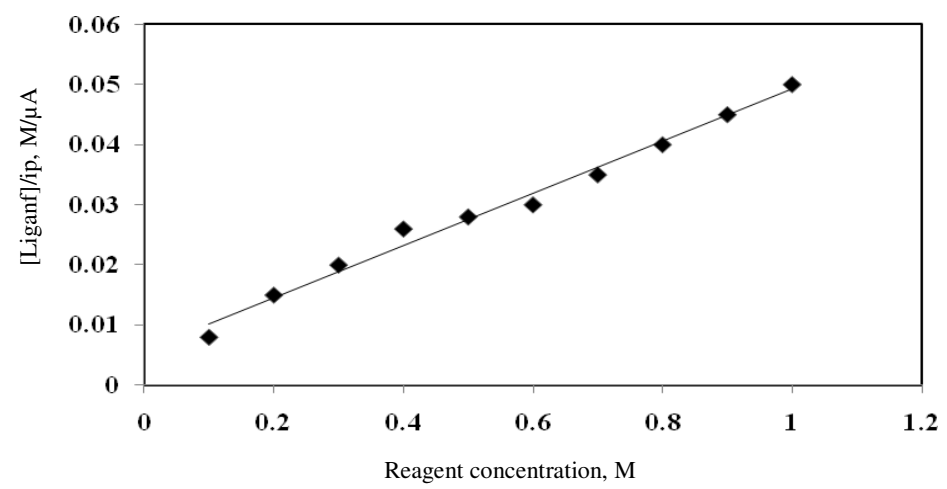

Figure 5. Langmuir adsorption isotherm plot for the determination of cerium(IV) in various drinking water samples using piperazine with catalytic current technique at DME

\section{Effect of mercury pressure}

The effect of the height of the mercury column on the polarograms of cerium(IV) (3.0 ppm) in quantitative experimental conditions was investigated and found that the catalytic current as well as $i_{C} / \sqrt{h}$ decreased with the height of the mercury column indicating that the current is catalytic in nature and the experimental observations are recorded in Table 1.

Table 1. Effect of mercury pressure for the determination of cerium(IV) in various water samples using piperazine with catalytic current technique at DME

\begin{tabular}{cccc}
\hline S.No & Height of the mercury column, cm & Current, $\mu \mathrm{A}$ & $i_{C} / \sqrt{h}$ \\
\hline 1 & 30 & 15.60 & 2.85 \\
2 & 35 & 15.10 & 2.55 \\
3 & 40 & 14.60 & 2.31 \\
4 & 45 & 14.10 & 2.10 \\
\hline
\end{tabular}

Conditions: $\mathrm{pH}$ 6.2; $\mathrm{NH}_{4} \mathrm{Cl} 0.15 \mathrm{M}$; Piperazine $0.5 \times 10^{-6} \mathrm{M}$; $\mathrm{Ce}(\mathrm{IV}) 3.0 \mathrm{ppm}$

\section{Effect of maximum suppressor}

The effect of surface active substance, Triton $X-100$ in 0.002 to $0.004 \%$ on the catalytic wave height was studied maintaining the fixed analytical concentration for ligand (Table 2). It is found that this surface active agent does not change the nature of the catalytic wave.

Table 2. Effect of maximum suppressors for the determination of cerium(IV) in various water samples using piperazine with catalytic current technique at DME

\begin{tabular}{ccc}
\hline S.No & Maximum suppressors & Current, $\mu \mathrm{A}$ \\
\hline Triton $\mathrm{X}-100$ & & \\
1 & 0.000 & 15.60 \\
2 & 0.002 & 13.90 \\
3 & 0.004 & 13.40 \\
\hline
\end{tabular}

Conditions: $\mathrm{pH}$ 6.2; $\mathrm{NH}_{4} \mathrm{Cl} 0.15 \mathrm{M}$; Piperazine $0.5 \times 10^{-6} \mathrm{M}$; $\mathrm{Ce}(\mathrm{IV}) 3.0 \mathrm{ppm}$ 


\section{Effect of temperature}

The current - voltage curves of the systems with ligand are recorded at various temperatures, i.e., 15 to $45{ }^{\circ} \mathrm{C}$ it is found that with increase in temperature the wave height and temperature coefficient values decreased gradually. The current, $i_{c}$ became completely temperature independent above $30^{\circ} \mathrm{C}$.

\section{Effect of cerium(IV) concentration on peak current}

At fixed concentrations of ligand, $\left(0.5 \times 10^{-6} \mathrm{M}\right.$ Piperazine) and $0.15 \mathrm{M}$ ammonium chloride adjusting the $\mathrm{pH}$ to 5.6 and 6.2 , respectively the metal ion concentration was varied between 0.1 to $4.0 \mathrm{ppm}$ and its effect on the current - voltage curves was studied. The peak current increased linearly with cerium(IV) concentration in the range 0.1 to $4.0 \mathrm{ppm}$ with ligand. The calibration plot is shown in Figure 6. The method suggests that the determination of micro - amounts of cerium(IV) is possible in unknown samples. It was observed that there was no change in the shape of the wave throughout the cerium(IV) concentration range studied.

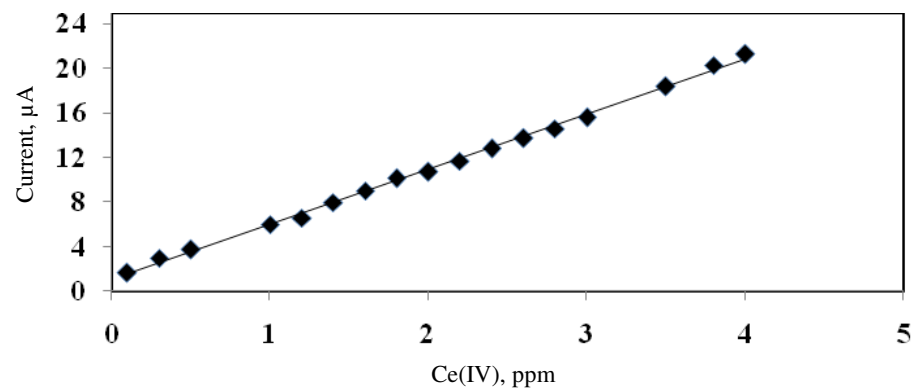

Figure 6. Effect of cerium(IV) on peak current for the determination of cerium(IV) in various drinking water samples using piperazine with catalytic current technique at DME

\section{Effect of foreign ions}

The effect of transition metal ions like $\mathrm{Ni}(\mathrm{II}), \mathrm{Cu}(\mathrm{II}), \mathrm{Mn}(\mathrm{II}), \mathrm{Fe}(\mathrm{II})$ and $\mathrm{Cr}(\mathrm{VI})$ which are commonly associated with $\mathrm{Ce}(\mathrm{IV})$, on the nature and height of the catalytic wave of cerium is studied using $3.0 \mathrm{ppm}$ Cerium(IV) in the quantitative experimental conditions developed. These metal ions do not interfere with $\mathrm{Ce}(\mathrm{IV})$ due to its specific conditions. Ni(II) gets precipitated below $\mathrm{pH} 9.0$ and $\mathrm{Fe}(\mathrm{II})$ at $\mathrm{pH} 8.0$ and above which can be filtered off. $\mathrm{Cr}$ (VI) does not interfere even when present up to 100 fold excess as its peak potential was negative to that of Cerium(IV). The other metal ions such as $\mathrm{Cd}(\mathrm{II}), \mathrm{Hg}(\mathrm{II}), \mathrm{V}(\mathrm{V}), \mathrm{Mg}(\mathrm{II}), \mathrm{Pb}$ (II), $\mathrm{Al}(\mathrm{III}), \mathrm{Ag}(\mathrm{I}), \mathrm{U}(\mathrm{VI}), \mathrm{Se}(\mathrm{IV}), \mathrm{Te}(\mathrm{IV})$ and $\mathrm{Sn}(\mathrm{IV})$, do not interfere with $\mathrm{Ce}(\mathrm{IV})$ even at 100 fold excess and $\mathrm{Zn}$ (II) up to $20 \mathrm{ppm}$. The only metal ion, Mo(VI) interferes seriously by increasing the wave height and shifting the peak potential of the Cerium(IV) catalytic wave. Anions such as fluoride, bromide, iodide, tatrate, sulphate, thiosulphate, perchlorate, carbonate, thiocyanate and phosphate do not interfere with cerium(IV) catalytic wave. Oxalate, citrate and EDTA interfere by completely suppressing the cerium catalytic wave, whereas nitrate and nitrate interfere by increasing the catalytic wave height.

\section{Effect of indifferent cations}

The effect of neutral salt and replacement of monovalent cation with divalent cation leads to changes both in the height and the potential location of the catalytic wave. The concentration of $\mathrm{NH}_{4} \mathrm{Cl}$ in the solution was kept constant and several amount of different chlorides were 
added to the polarographed solutions of $3.0 \mathrm{ppm} \mathrm{Ce}(\mathrm{IV})$ in fixed concentrations of ligand at corresponding $\mathrm{pH}$ values. Three alkali chlorides potassium, sodium and lithium and bivalent cation, calcium were used. With increase in concentration of chlorides the wave height decreased continuously and the decrease of wave height in sodium chloride is slightly less to that of potassium chloride. The decrease is more for lithium chloride and much more for calcium chloride as shown in Figure 7.

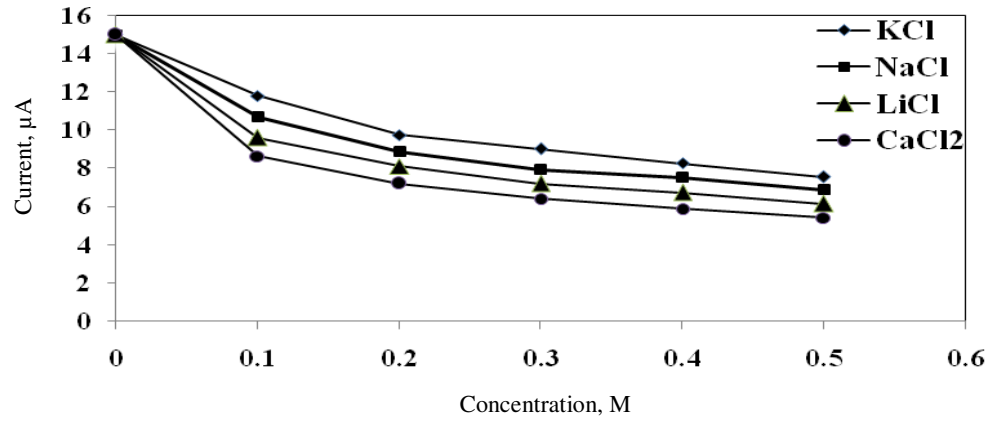

Figure 7. Effect of indifferent ions on piperazine - cerium(IV) complex at DME for the determination of cerium(IV) in various drinking water samples using catalytic current technique

\section{Applications}

The catalytic polarographic method was extended for the analysis of trace amount of cerium(IV) in water samples.

\section{Determination of cerium(IV) in water samples}

One liter of the water samples collected from Kalyani Dam and Bore well, (Tirupati town, Chittoor Dt.) are preconcentrated and analyzed. The results, in Table 3, indicate that the water.

Table 3. Determination of cerium(IV) in water samples of Tirupati town

\begin{tabular}{cccccc}
\hline \multirow{2}{*}{ Sample $^{*}$} & $\begin{array}{c}\text { Z } \\
\text { s }\end{array}$ & $\begin{array}{c}\text { Ce(IV) } \\
\text { added, ppm }\end{array}$ & $\begin{array}{c}\text { Catalytic method } \\
\text { Ce(IV) found, } \\
\text { ppm }\end{array}$ & $\begin{array}{c}\text { DPP method } \\
\text { Ce(IV) found, } \\
\text { ppm }\end{array}$ & $\begin{array}{c}\text { Recovery, } \\
\%\end{array}$ \\
\hline \multirow{4}{*}{ I } & 1 & 0.5 & 0.49 & 0.48 & 98.00 \\
& 2 & 1.0 & 1.00 & 1.02 & 100.00 \\
& 3 & 1.5 & 1.49 & 1.50 & 99.33 \\
& 4 & 2.0 & 1.97 & 1.95 & 98.50 \\
& 5 & 2.5 & 2.50 & 2.45 & 100.00 \\
& 1 & 0.5 & 0.50 & 0.52 & 100.00 \\
II & 2 & 1.0 & 1.00 & 1.05 & 100.00 \\
& 3 & 1.5 & 1.48 & 1.50 & 98.66 \\
& 4 & 2.0 & 1.99 & 1.95 & $99 . .50$ \\
& 5 & 2.5 & 2.50 & 2.49 & 100.00 \\
\hline
\end{tabular}

*5 $\mathrm{mL}$ of the concentrated sample was used. Condition: $\mathrm{pH}=6.2, \mathrm{NH}_{4} \mathrm{Cl}=0.15 \mathrm{M}$,

Piperazine $=0.5 \times 10^{-6} \mathrm{M}$; I Kalyani Dam, II Bore well.

Samples contain slightly high concentration levels of cerium(IV). The results of cerium(IV) compare with differential pulse polarography. The typical differential pulse polarographic curves are shown in Figure 8. 


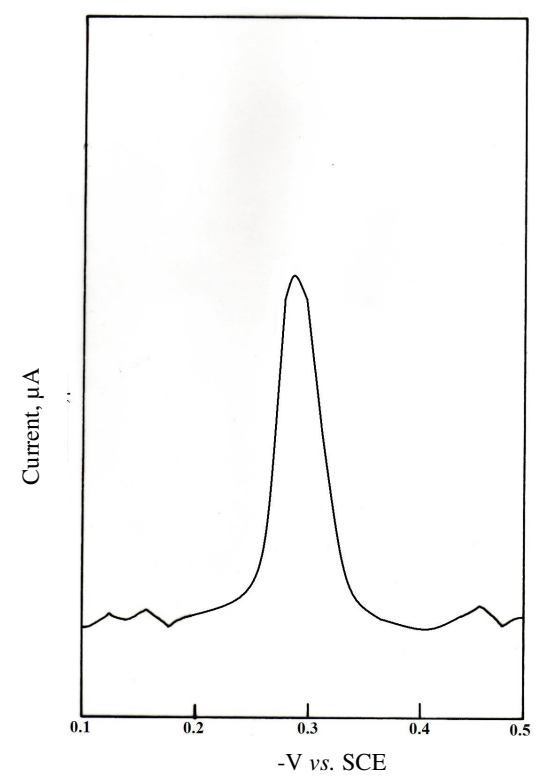

Figure 8. Differential Pulse Polarographic curve of cerium(IV) in $\mathrm{NH}_{4} \mathrm{Cl}-\mathrm{NH}_{4} \mathrm{OH}$ medium in the presence of Piperazine. (Current range : $100 \mu \mathrm{A}$, Scan rate: $6 \mathrm{mV} / \mathrm{S}$, Pulse Amplitude: 50 $m$ V Drop time: $1 \mathrm{Sec}$, Cerium(IV) : $0.001 \mathrm{ppm})$

\section{Conclusion}

The analysis of $\mathrm{Ce}(\mathrm{IV})$ with piperazine $\mathrm{NH}_{4} \mathrm{OH}-\mathrm{NH}_{4} \mathrm{Cl}$ buffer gives catalytic hydrogen wave and its $\mathrm{pH}$ effect and $\mathrm{NH}_{4} \mathrm{Cl}$ concentration clear indicates the characteristic property of catalytic surface reaction.

The non linear portion has the shape of a curve resembling a Langmuir adsorption isotherm and therefore the plot of $\left\{[\right.$ Ligand $\left.] / i_{P}\right\}$ vs. [Ligand] is a straight line. This dependence is due to the adsorption of the catalytically active compound at the electrode surface.

All the observations clearly indicate that the catalytic current is of Bridicka type. When current is less then $20 \%$ of its limiting value, it is entirely kinetic in nature(pH effects) and at maximum or limiting current or saturation value it is diffusion controlled (RSH and Co(II) effects). Between 20 and 100\% Bridicka currents exhibit mixed kinetic diffusion character. In total it is adsorption - kinetic - diffusion controlled combination that plays in determining the nature of the catalytic hydrogen waves. The present method has the following advantage

1. It is facile, sensity and reproducible for determination of $\mathrm{Ce}(\mathrm{IV})$ in various water system.

2. The ligand is fairly soluble in water, this indicate the eco - friendly nature of the ligand.

3. The developed method is successfully applied for the determination of Ce(IV) in various water systems and results obtained were in good agreement with D.P.P method.

\section{Acknowledgement}

The authors are highly thankful to The Head of the Department of Chemistry SVU for providing necessary facilities. 


\section{References}

1. Smith G F, Cerate Oxidimetry, $2^{\text {nd }}$ Ed., Smith G F, Chemical Co. Columbus, OH, 1964.

2. Ho T L, Synthesis, 1973, 347-354.

3. Vining W J and Meyer T J, Inorg Chem., 1986, 5, 2023-2033; Ellis C D, Gillbert J A, Murphy W R and Jr Meyer T J, J Am Chem Soc., 1983, 105, 4842- 4843.

4. Kiwi J and Gratzel M, Chem Phys Lett., 1981, 78, 241-245; Mills A and Cook A J, Chem Soc Faraday Trans I, 1988, 84, 1691-1701; Mills A and Susan Giddings, Inorg Chim Acta, 1990, 158, 49-57.

5. Cotton F A and Wilkinson G, Adv Inorg Chem, New Delhi, Wiley Eastern, 1976.

6. Toxicity of Heavy Metals in the Environment, Oehme F W, Ed., New York, Marcel Dekker, 1979.

7. Qunzhou B, Subiao P, Bailim H, Zhiguang Z and Weiliang G, Yuansu Kexue, 1999, 6, 64, Chem Abstr., 1999, 131m, 82253v.

8. Yuping H and Luming L, Guangpu Shiyanshi, 1998, 15, 51, Chem Abstr., 1999, 130, 118788 u.

9. Liang D-Ping, Fenxi Shiyanshi, 2000, 19, 67; Chem Abstr., 2000, 133, $217008 \mathrm{~h}$.

10. Qin S, Yongehao Q, Bin H, Hongehun X and Zucheng J, Anal Sci., 2000, 16(9), 957.

11. Shuai Q, Bin H, Qin Y, Ruth W and Jiang Z, J Anal At Spectrochem., 2000, 15, 1413.

12. Yener R and Aycicek A, J Fluorese, 1998, 8, 45-52.

13. Jie N, Yang J and Liu T, Talanta, 1994, 41(3), 415-417.

14. Matakova R N, Kenzhekhanova Zh T and Badavamova G L, J Anal Chem., 1999, 54(11), 1053-1055.

15. Beng K S and Jing Z, Electroanalysis, 1999, 11, 546.

16. Marczenko Z, Separation and Spectrophotometric Determination of Elements, Ellis Hor Wood, Chichester, 1986.

17. Chen N S, Wang L L, Zhuo Z J and Guo X Y, Chin J Rare Earth (in Chinese), 2003, 27(4), 517.

18. Zhou Z R, Zhang L Z and Wang L, Food Sci (in Chinese), 2005, 26(3), 192.

19. Tang N L, Phys Test Chem Anal Part B (in Chinese), 2006, 42(3), 213.

20. Wang X.Z, Guo H.M, Tang T and Huang C, Chin J Anal Lab (in Chinese), 2001, 20(3), 47.

21. He R H, Jiang H, Wang J H and Sun H B, Rare Met Mater Eng (in Chinese), 1998, 27(2), 115. 